\title{
Avaliação da atividade dos inibidores de tripsina após digestão enzimática em grãos de soja tratados termicamente ${ }^{1}$
}

\section{Evaluation of trypsin inhibitors activity after enzymatic digestion in heat-treated soybean}

Maria Regina Barbieri de CARVALHO2

Peter Gaberz KIRSCHNIK²

Kelli Cristina PAIVA ${ }^{2}$

Felipe Shindy AIURA ${ }^{2}$

R E S U M O

Este trabalho avalia a reativação dos inibidores de tripsina, após proteólise in vitro, de grãos de soja tratados termicamente. Para a inativação térmica dos inibidores, os grãos foram embebidos em água destilada $(1: 5 \mathrm{p} / \mathrm{v})$ durante 12 horas e aquecidos em placas sob refluxo por 30 minutos. A reativação dos inibidores foi avaliada em comparação com a atividade das amostras cruas e aquecidas. A digestibilidade in vitro das proteínas variou de 47\% ('OC-13') a 59\% (Paraná), apresentando uma melhora, em média, de 32,6\% com o aquecimento. A atividade dos inibidores de tripsina para os grãos crus variou de 122 a $206 \mathrm{UTI} / \mathrm{mg}$ de amostra, e os valores correlacionaram-se negativamente com a porcentagem de digestibilidade $(r=-0,9177)$. Os inibidores tiveram suas atividades totalmente inativadas com o aquecimento dos grãos, os quais apresentaram porcentagem de recuperação, em média, de 40\%. Com o aquecimento, a inativação dos inibidores provavelmente ocorre por complexação com os componentes do grão, o que leva à recuperação da atividade com o processo de digestão enzimática.

Termos de indexação: inibidores de tripsina, inativação térmica, digestibilidade in vitro, reativação, digestão enzimática, feijão de soja.

A B S T R A C T

This work evaluates the trypsin inhibitors reactivation, after in vitro proteolysis, of heat-treated soybean. For the inhibitors thermal inactivation, soybeans were soaked in distilled water $(1: 5 \mathrm{p} / \mathrm{v})$ during 12 hours and

\footnotetext{
1 Pesquisa parcialmente financiada pela Fundação de Amparo à Pesquisa de São Paulo (FAPESP), Processo n. 98/06748-5.

2 Departamento de Tecnologia, Faculdade de Ciências Agrárias e Veterinárias, Universidade Estadual Paulista. Rodovia Paulo Donato Castellani, 14884-900, Jaboticabal, SP, Brasil. Correspondência para/Correspondence to: M.R.B. CARVALHO.E-mail: mrbcar@fcav.unesp.br
} 
heated on reflux plates for 30 minutes. The inhibitors reactivation was evaluated in comparison with the activity of raw and heated samples. The in vitro digestibility of proteins ranged from $47 \%$ ('OC-13') to $59 \%$ ('Parana'), showing an average progress of $32.6 \%$ with the heating. The trypsin inhibitors activity ranged from 122 to $206 \mathrm{UTI} / \mathrm{mg}$ for the raw sample, and the values correlated negatively with the digestibility percentage $(r=-0.9177)$. The inhibitors had the activities totally inactivated with the heating of soybeans, which showed an average recovering percentage of $40 \%$. With the heating, the inactivation of inhibitors probably takes place by complexing with the soybean components, which leads to the recovering of activity with the enzymatic digestion process.

Index terms: trypsin inhibitors, thermal inactivation, in vitro digestibility, reactivation, soybeans.

\section{N T R O D U Ç Ã O}

Nos grãos das leguminosas verifica-se a ocorrência natural dos inibidores de tripsina. A sua presença no trato intestinal inibe a ação da tripsina, que é responsável pela digestão das proteínas, levando a um aumento na produção enzimática pelo pâncreas e à hipertrofia deste órgão.

$\mathrm{Na}$ nutrição humana tais fatores antinutricionais têm pequena conseqüência, pois são termolábeis e geralmente são destruídos nas condições normais de preparo, doméstico ou industrial, dos alimentos (Ojimelukwe et al., 1995). No entanto, a utilização cada vez maior de alimentos naturais ou o uso de baixas temperaturas de cozimento podem expor a população aos seus efeitos deletérios.

Vários procedimentos têm sido adotados para o tratamento térmico dos grãos, implicando em inativação dos fatores antinutricionais e em mudanças na estrutura das proteínas, elevando a digestibilidade destes nutrientes.

0 aquecimento térmico tem-se mostrado bastante eficiente para os grãos inteiros, mas com efeitos reduzidos ou mesmo ineficientes quando se trata da farinha ou de inibidores purificados (Rayas-Duarte et al.,1992; Carvalho \& Sgarbieri, 1997). Ellenrieder et al. (1980) concluíram que componentes de alto peso molecular, separados dos extratos de soja por filtração em gel de Sephadex G-75, aceleraram a inativação térmica dos inibidores de tripsina. Segundo Tsukamoto et al. (1983), proteínas, polissacarídeos e ácidos nucléicos provenientes do feijão são fatores inativantes, pela interação com os inibidores, e, de acordo com Galeazzi \& Sgarbieri (1988), a ação do calor leva os inibidores a se complexarem com os componentes do grão, não sendo, portanto, eliminados. Desta forma, ainda não existe consenso das condições de aquecimento mais adequadas para a inativação dos inibidores de tripsina. Assim, realizou-se este trabalho com o objetivo de avaliar a reativação desses inibidores após a proteólise in vitro de amostras de grãos de soja tratados termicamente.

\section{ATERIALE MÉTO DOS}

Foram utilizados cinco cultivares de soja (Glycine max L. Merril): IAC-17, IAC-31, Paraná, OC-13 e CAC-1.

Os grãos de soja, após maceração em água destilada (1:5 p/v) durante 12 horas em temperatura ambiente, foram aquecidos em água fervente, sob refluxo, por 30 minutos. Após resfriamento rápido em banho de gelo, as amostras foram secas em estufa $\left(60^{\circ} \mathrm{C}\right) \mathrm{com}$ circulação de ar e moídas até a granulometria de 70 mesh.

A extração dos inibidores foi realizada agitando-se, durante uma hora em temperatura ambiente, 0,5 g da amostra (previamente desengordurada a frio, com éter de petróleo) em $25 \mathrm{~mL}$ de $\mathrm{HCl}$ 0,025 M. A suspensão foi então filtrada em papel Whatman n.2 e o filtrado 
utilizado para determinação da atividade dos inibidores de tripsina. Esta atividade, em amostras cruas, tratadas termicamente e hidrolisadas, foi determinada utilizando-se o benzoil-DL-arginina-p-nitroanilida (BAPNA) como substrato para a tripsina, conforme procedimentos descritos por Kakade et al. (1969).

A líquotas do extrato protéico 0,2 a $1,0 \mathrm{~mL}$ foram pipetadas, em triplicatas, e o volume final foi ajustado para $1 \mathrm{~mL}$ com tampão Tris $50 \mathrm{mM}$, $\mathrm{pH} 8,2$, contendo $\mathrm{CaCl}_{2} 20 \mathrm{mM}$. A cada tubo, previamente acondicionado em banho-maria a $37^{\circ} \mathrm{C}$, adicionaram-se $1 \mathrm{~mL}$ da solução de tripsina $(0,08 \mathrm{mg} / \mathrm{mL}$ de $\mathrm{HCl} 0,001 \mathrm{~N})$ e, após 10 minutos, $7,0 \mathrm{~mL}$ de BAPNA $(0,3 \mathrm{mg} / \mathrm{mL}$ de tampão Tris 50 $\mathrm{mM}, \mathrm{pH} 8,2$, contendo $\mathrm{CaCl}_{2} 20 \mathrm{mM}$ ), previamente aquecidos a $37^{\circ} \mathrm{C}$. A reação foi interrompida após 10 minutos pela adição de 1,0 mL de ácido acético 30\% . A absorbância foi lida a $410 \mathrm{~nm}$, contra os brancos aos quais adicionou-se o ácido acético antes do BAPNA. Uma unidade de tripsina (UT) foi definida arbitrariamente como o aumento de 0,01 unidade de absorbância a $410 \mathrm{~nm}$ por $10 \mathrm{~mL}$ do meio de reação. Os resultados foram expressos como unidades de tripsina inibida (UTI) por mg de amostra.

A digestibilidade in vitro foi determinada, basicamente, segundo o procedimento de Akeson \& Stahman (1964), o qual utiliza um sistema enzimático composto por pepsina/pancreatina e ácido tricloroacético (TCA) para a precipitação da proteína não hidrolisada. No hidrolisado foram identificadas a quantidade de nitrogênio (método semi-microkjeldahl) e a atividade dos inibidores de tripsina.
A porcentagem de digestibilidade foi determinada correlacionando-se o nitrogênio total da amostra analisada com o nitrogênio contido no hidrolisado. A reativação dos inibidores de tripsina foi avaliada em comparação com a atividade das amostras cruas.

\section{RESULTA D OS E DISCUSSÃ O}

A qualidade nutricional dos cultivares de soja em estudo foi avaliada através da digestibilidade in vitro das proteínas e os resultados obtidos (Tabela 1) evidenciam uma variação de $47 \%$ ('OC-13') a 59\% ('Paraná'). Com o aquecimento dos grãos em água fervente, houve uma melhora na digestibilidade, ocorrendo um acréscimo, em média, de $32,6 \pm 5,94 \%$. Os cultivares OC-13 e CAC-1 apresentaram os menores valores, tanto para a amostra crua quanto para a aquecida; no entanto, obtiveram os maiores acréscimos após o tratamento térmico, ou seja, $38 \%$ e $39 \%$, respectivamente. A melhora na digestibilidade com o tratamento térmico é atribuída às alterações estruturais das proteínas, aumentando a susceptibilidade à hidrólise enzimática (Deshpande \& Damodaran, 1989; Carbonaro et al., 1992).

A atividade variou de 122 a 206 UTI/mg de amostra, respectivamente, para os cultivares Paraná e OC-13. Os inibidores de tripsina estão envolvidos com as funções fisiológicas das plantas, e a sua presença, ainda que em proporções variáveis, durante o ciclo vital das sementes, sugere sua importância ao vegetal (Tabela 2 ).

Tabela 1 Valores médios obtidos para a digestibilidade in vitro das amostras cruas e aquecidas (\%).

\begin{tabular}{lccc}
\hline \multirow{2}{*}{ Cultivares } & \multicolumn{2}{c}{ Digestibilidade } & \% de acréscimo \\
\cline { 2 - 3 } & amostra crua (\%) & amostra aquecida (\%) & 29 \\
\hline IAC-17 & 55 & 71 & 25 \\
IAC-31 & 55 & 69 & 32 \\
Paraná & 59 & 78 & 38 \\
OC-13 & 47 & 65 & 39 \\
CAC-1 & 49 & 68 & 39 \\
\hline
\end{tabular}


Tabela 2 Valores médios para atividades dos inibidores de tripsina e porcentagem de recuperação.

\begin{tabular}{lccc}
\hline \multirow{2}{*}{ Cultivares } & \multicolumn{2}{c}{$\mathrm{UTI}^{(1)} / \mathrm{mg}$} & \% de recuperação \\
\cline { 2 - 3 } & amostra crua (\%) & amostra aquecida e digerida (\%) & 40 \\
\hline IAC-17 & 129 & 51 & 40 \\
IAC-31 & 132 & 53 & 38 \\
Paraná & 122 & 46 & 46 \\
OC-13 & 206 & 95 & 36 \\
CAC-1 & 160 & 57 & 36 \\
\hline
\end{tabular}

(1) UTI = unidades de tripsina inibidas.

Os inibidores de tripsina, presentes nos cultivares de soja analisados, tiveram suas atividades totalmente inativadas com 0 aquecimento dos grãos em água fervente por 30 minutos. A sua estabilidade térmica é bastante variada, estando na dependência, entre outros fatores, da temperatura, duração e forma de aquecimentos, do tamanho das partículas, do conteúdo de umidade, da conformação estrutural do inibidor. Em alguns cultivares de feijão a atividade dos inibidores é destruída em menos de 10 minutos, com aquecimento a $120^{\circ} \mathrm{C}$, enquanto em outros ela pode ser detectada após 60 minutos de tratamento a $100^{\circ} \mathrm{C}$ (Sgarbieri \& Whitaker, 1982). A resistência oferecida pelos inibidores à inativação térmica pode ser devida à sua configuração compacta, como conseqüência do elevado número de ligações dissulfídicas nas suas moléculas (Sgarbieri \& Whitaker, 1982).

A presença dos inibidores de tripsina nos grãos de leguminosas contribuem para a redução da digestibilidade de suas proteínas (Liener, 1979). Esta situação também foi verificada neste estudo, pois os valores de atividade dos inibidores correlacionaram-se negativamente $(r=-0,9177)$ com a porcentagem de digestibilidade. Deste modo, o cultivar OC-13, que apresentou a maior atividade para os inibidores (206 UTI/mg de amostra), obteve o menor valor para digestibilidade in vitro $(47 \%)$.

Os resultados obtidos para a atividade dos inibidores de tripsina nos grãos tratados termicamente e submetidos à digestão enzimática, bem como as porcentagens de recuperação da atividade em relação à amostra crua, estão apresentados, também, na Tabela 2.
A atividade variou de $46 \mathrm{UTI} / \mathrm{mg}$ de amostra ('Paraná') a 95 UTI/mg de amostra ('OC-13'), havendo uma correlação positiva $(r=0,9656)$ com os valores de atividade dos grãos crus. A porcentagem de recuperação da atividade foi, em média, 40 $\pm 3,74 \%$, sendo o maior valor observado para o cultivar OC-13 (46\% ). Galeazzi \& Sgarbieri (1988) também observaram a regeneração, em até $100 \%$ da atividade, após digestão enzimática de amostras de feijão autoclavadas.

0 mecanismo de inativação pode ocorrer, portanto, pela complexação dos inibidores. Desse modo, com a ação do calor os inibidores se ligam com outros componentes do grão e se tornam inativos, indicando assim que essa inativação não deve ter ocorrido pela desnaturação térmica das moléculas dos inibidores. Ao serem submetidos à hidrólise enzimática, apresentam-se novamente ativos, mostrando que a ação do calor é benéfica na inativação dos inibidores, porém não os elimina completamente.

Os inibidores de tripsina apresentam características próprias em relação à sua hidrólise proteolítica. 0 inibidor do tipo Bowman-Birk não é hidrolisado pela papaína (Sgarbieri, 1979) nem pela pepsina (Tsukamoto et al., 1983), enquanto o tipo Kunitz tem esta propriedade em relação a estas duas substâncias (Vaintraub \& Yattara, 1995).

Em um estudo sobre a ação das enzimas pepsina e papaína sobre a atividade do inibidor de Kunitz da soja, foi observado que a hidrólise degradava os inibidores em peptídeos pequenos, os quais retinham toda a atividade inibitória (Vaintraub \& Yattara, 1995). Esse inibidor possui baixos teores de meia cistina e de grupos ácidos 
nas moléculas(Sgarbieri, 1979), conferindo-Ihe a propriedade de sofrer alterações conformacionais e desnaturação parcial em meio ácido, de maneira a expor as ligações peptídicas à ação da pepsina.

Os inibidores do tipo Bowman-Birk, em virtude da predominância de grupos ácidos na molécula e do elevado teor de pontes dissulfeto, apresentam resistência à desnaturação, tanto térmica como pela ação da pepsina (Sgarbieri, 1979).

Como na soja estão presentes os dois tipos de inibidores, tem-se a possibilidade de estes alcançarem o trato gastrointestinal nas suas formas ativas, pois se apresentam resistentes à hidrólise enzimática, ou, quando fragmentados, retêm a atividade inibitória.

A regeneração da atividade de inibidor de tripsina em amostras tratadas termicamente e hidrolisadas in vitro pode ser conseqüência dos seguintes fatores: interação dos inibidores, por ação do calor, com outras substâncias próprias do grão, levando-os à inativação; e retenção da atividade inibitória pelos fragmentos obtidos com a degradação proteolítica.

\section{O N C L U S Ã O}

O tratamento térmico inativou os inibidores de tripsina e elevou a digestibilidade in vitro da proteína. Esta inativação, com o aquecimento, parece ocorrer por complexação com os componentes do grão, o que leva à recuperação da atividade com o processo de digestão.

\section{REFERÊ NCIAS B I B L I O G RÁ F I C A S}

AKESON, W.R., STAHM AN, M .A. A pepsin pancreatin digest index of protein quality evaluation. Journal of Nutrition, Bethesda, v.83, n.3, p.257-261, 1964.

CARBONARO, M., MARLETTA, L., CARNOVALE, E. Factors affecting cystine reactivity in proleolytic digests of Phaseolus vulgaris. Journal Agricultural
Food Chemistry, Washington DC, v.40, n.2, p.169-173, 1992.

CARVALHO, M.R.B., SGARBIERI, V.C. Heat treatment and inactivation of trypsin: chymotrypsin inhibitors and lectins from beans (Phaseolus vulgaris L.). Journal Food Biochemistry, Westport, v.21, n.3, p.219-233, 1997.

DESHPANDE, S.S., DAM ODARAN, S. Structure: a digestibility relationship of legume $7 \mathrm{~S}$ proteins. Journal Food Science, Chicago, v.54, n.1, p.108-113, 1989.

ELLENRIEDER, G., GERONASO, H., DE BOJARSKI, A.B. Thermal inactivation of trypsin inhibitors in aqueous extracts of soybeans, peanuts and kidney beans: presence of substances that accelerate inactivation. Cereal Chemistry, Saint Paul, v.57, n.1, p.25-27, 1980

GALEAZZI, M.A.M., SGARBIERI, V.C. Inactivation and reactivation of trypsin inhibitors in different bean varieties. In: ORGANIZATION of the American States. Advances in bean research: chemistry, nutrition, technology. São Paulo : EDUSP, 1988. p.15.

KAKADE, M .L., SIM ONS, N., LIENER, I.E. An evaluation of natural vs synthetic substract for measuring the antitryptic of soybean samples. Cereal Chemistry, Saint Paul, v.46, n.4, p.518-526, 1969.

LIENER, I.E. The nutritional significance of plant protease inhibitor. Proceedings of the Nutrition Society, Cambridge, v.38, n.1, p.109-113, 1979.

OJIMELUKWE, P.C., ONUOHA, C.C., OBANU, Z.A. Effect of processing in vivo proteolytic digestion on soybean and yambean hemagglutinins. Plant Foods for Human Nutrition, Doidrech, v.47, n.3, p.293-299, 1995.

RAYAS-DUARTE, P., BERGERON, D., NIELSEN, S.S. Screening of heat-sable inhibitor trypsins in dry beans and their partial purification from great Northern beans (Phaseolus vulgaris) using anhydrotrypsin sepharose affinity chromatography. Journal Agricultural Food Chemistry, Washington DC, v.40, n.2, p.32-42, 1992.

SGARBIERI, V.C. Propriedades físico-químicas e nutricionais de proteínas de feijão (Phaseolus vulgaris,..) var. Rosinha G2. Campinas, 1979. 207p. 
Tese (Livre-Docência) - Faculdade de Engenharia de Alimentos e Agrícola, Universidade Estadual de Campinas, 1979.

SGARBIERI, V.C., WHITAKER, J.R. Physical, chemical and nutritional properties of common bean (Phaseolus) proteins. Advance Food Research, Orlando, v.28, n.1, p.93-166, 1982.

TSUKAM OTO, I., MIYOSHI, M., HAMAGUCHI, Y. Purification and characterization of trypsin inhibitors from beans Phaseolus vulgaris 'Kintoki'. Cereal Chemistry, Saint Paul, v.60, n.3, p.281-286, 1983.

VAINTRAUB, I.A., YATTARA, H.B. Proteolysis of kunitz soybean trypsin inhibitor. Influence on its activity. Journal Agricultural Food Chemistry, Washington DC, v.43, n.4, p.862-866, 1995.

Recebido para publicação em 5 de setembro de 2000 e aceito em 7 de novembro de 2001. 